\title{
Quality of Life Impact Related to Foot Health in a Sample of Older People with Hallux Valgus
}

\author{
Daniel López López ${ }^{1 * *}$, Lucía Callejo González ${ }^{1}$, Marta Elena Losa Iglesias², Jesús Luis Saleta \\ Canosa ${ }^{1}$, David Rodríguez Sanz ${ }^{3}$, Cesar Calvo Lobo ${ }^{3}$, Ricardo Becerro de Bengoa Vallejo ${ }^{4}$ \\ ${ }^{1}$ Research, Health and Podiatry Unit, Department of Health Sciences, Faculty of Nursing and Podiatry, \\ Universidade da Coruña, Spain. \\ ${ }^{2}$ Faculty of Health Sciences, Universidad Rey Juan Carlos, Spain. \\ ${ }^{3}$ Department, Faculty of Health, Exercise and Sport, European University of Madrid, Villaviciosa de Odón, \\ Madrid, Spain. \\ ${ }^{4}$ School of Nursing, Physiotherapy and Podiatry. Universidad Complutense de Madrid, Spain.
}

[Received August 2, 2015; Revised September 10, 2015; Accepted September 14, 2015]

\begin{abstract}
Hallux Valgus (HV) is a highly prevalent forefoot deformity in older people associated with progressive subluxation and osteoarthritis of the first metatarsophalangeal (MTP) joint and it is believed to be associated with varying degrees of $\mathrm{HV}$ effect on the quality of life related to foot health.The aim of this study is to compare the impact of varying degrees of $\mathrm{HV}$ on foot health in a sample of older people. The sample consisted of 115 participants, mean age 76.7 \pm 9.1 , who attended an outpatient center where self-report data were recorded. The degree of $\mathrm{HV}$ deformity was determined in both feet using the Manchester Scale (MS) from stage 1 (mild) to 4 (very severe). Scores obtained on the Foot Health Status Questionnaire (FHSQ) were compared. This has 13 questions that assess 4 health domains of the feet, namely pain, function, general health and footwear. The stage 4 of HV shown lower scores for the footwear domain (11.23 \pm 15.6$)$; general foot health (27.62 \pm 19.1$)$; foot pain $(44.65 \pm 24.5)$; foot function $(53.04 \pm 27.2)$; vigour $(42.19 \pm 16.8)$; social capacity (44.46 \pm 28.1$)$; and general health $(41.15 \pm 25.5)$ compared with stage 1 of $\mathrm{HV}(\mathrm{P}<0.05)$ and there were no differences of physical activity $(62.81 \pm 24.6)$. Often, quality of life decreases in the elderly population based in large part on their foot health. There is a progressive reduction in health in general and foot health with increasing severity of hallux valgus deformity which appears to be associated with the presence of greater degree of $\mathrm{HV}$, regardless of gender.
\end{abstract}

Key words: Foot Deformities, Foot diseases, Hallux Valgus, Musculoskeletal Diseases, Quality of Life.

Hallux valgus (HV) is a common condition in older people, with higher prevalence rates (up to $74 \%$ ) observed in institutional and clinical settings [1, 2], but its association with significant functional disability, foot pain and other factors is unclear in a population setting [3-10]. $\mathrm{HV}$ is a complex deformity of the first metatarsophalangeal (MTP), in which no two cases are identical $[11,12]$. It is characterized by lateral drift of the great toe in association with joint subluxation $[13,14]$. Its progression is multifactorial, complex, poorly understood [16] and it is sometimes accompanied by the presence of pain, keratotic lesions, muscle weakness in the area, changes in the lesser toes, increased mediolateral postural sway, variation in plantar pressures and difficulties putting shoes on $[15,16]$. This condition is recognized as a major public health problem [9], with the negative impact of HV posing a significant burden on public and individual health given the high incidence related to orthopedic foot surgery $[17,18]$ and its association with pain at the low back [20,21], hip [21, 22], knee [23], osteoarthritis[24] (OA) in the first MTP joint [19], gait disturbance[25, 26] and risk of falls [27, 28]. However,

*Correspondence should be addressed to: Dr. Daniel López López, Universidade da Coruña, Unidade de Investigación Saúde e Podoloxía, Departamento de Ciencias da Saúde, Spain Email: daniellopez@udc.es 
the effects of varying degrees of HV on the quality of life related to foot health by older people with is unclear. It has been reported that significant improvement in quality of life can be attained after surgery for HV [29], while other reports note differences in foot health status between $\mathrm{HV}$ and hallux rigidus in patients receiving surgical consultation appear to have a negative impact on health status [30]. For patients who suffer from this chronic disease [31], it is important to consider illnesses and deformities of the foot, postural alterations and other basic illnesses as factors to be taken into account when planning treatment and preventive care activities in the attempt to find a better quality of life. Thus, the aim of this study was to describe and compare the impact related scores obtained with regard to foot health and overall health in a sample of older people with varying degrees of $\mathrm{HV}$.

\section{MATERIALS AND METHODS}

\section{Design and sample}

This is a descriptive observational study carried out in a health centre between September 2014 and April 2015. The selection of the cases subject to study was made by consecutive sampling, the criterion for inclusion being aged 65 or over. Exclusion criteria: people with depression, people who had experienced previous trauma and feet surgery records, neurologic alterations, or lack of or partial autonomy in daily activities, as well as those who refused to sign the consent form or were incapable of understanding the instructions necessary to carry out the present study.

\section{Procedure}

All measurements were carried out by one single researcher. The height, weight and body mass index (BMI) of the informants were calculated in the first place. To determine the severity of hallux valgus using the Manchester scale, life-size versions of the photographs in the original publication were printed and laminated [32]. This scale describes a noninvasive method of assessing the severity of HV deformity by means of a set of standardized photographs on a scale of 1 (no deformity) to 4 (severe deformity) and the reliability of the four-point scale for the severity of hallux valgus showed and excellent inter-observer repeatability with a combined kappa-type statistic of 0.86 , making it a suitable instrument for clinical and research purposes [33]. Also, the validity of photographic measurements of HV angle compared to radiographs showed an interrater reliability very high (intraclass correlation coefficients greater than 0.96 ) and $95 \%$ limits of agreement between photographic and radiographic measurements were acceptable.
Measurements from photographs and radiographs were also highly correlated (Pearson $r=0.96$ ). Digital photographic measurements of hallux valgus angle are reliable and have acceptable validity compared to weightbearing radiographs. This method provides a convenient and precise tool in assessment of hallux valgus, while avoiding the cost and radiation exposure associated with radiographs [34].

Subjects stood on an elevated platform and were instructed to walk in place for a few steps and then stand in a relaxed position. The examiner placed the photographs alongside subjects' weight-bearing feet, and selected which photograph most closely resembled their degree of hallux valgus [35]. The severity of hallux valgus for both feet was then documented as no deformity (grade 1 ), mild deformity (grade 2), moderate deformity (grade 3 ) or severe deformity (grade 4) [33].

After that, informants filled out the Foot Health Status Questionnaire (FHSQ) [32]. This self-administered questionnaire on health-related quality of life is intended specifically for the foot which is recognised as a validated test [36, 37].Foot-specific and general health-related quality of life was assessed by using the Foot Health Status Questionnaire (version 1.03) [37], which comprises three main sections. Section 1 consists of 13 questions reflecting four foot health-related domains (Table 1): foot pain, foot function, footwear, and general foot health. This section has demonstrated a high degree of content, criterion, and construct validity (Cronbach $\alpha=0.89-0.95$ ) and high retest reliability (intraclass correlation coefficient $=0.74-0.92$ ) [37] and it has been shown to be the most appropriate measure of health-related quality of life for chronic plantar heel pain population [38].

Each domain has a specific number of questions (Table 2). Four regarding pain, 4 on function, 3 on footwear and 2 on general foot health. The assessment of pain and function is based on physical phenomena, the evaluation of footwear uses practical aspects related to availability and the comfort of the shoes, while the perception of the foot's general health is based on the patients' selfassessment of the state of their feet. Each question allows several answers and these are placed on a Likert-type ordinal scale (words or phrases corresponding to a numeric scale). The descriptors for these scales vary for each domain and the person completing the questionnaire has to choose only one response, whichever is thought to be the most appropriate. The questionnaire does not provide a global score, but rather generates an index for each domain. In order to obtain these indices, the responses are analysed by a computer program (The FHSQ, Version 1.03) which, after processing the data, gives a score ranging from 0 to 100 . A 0 score represents the worst state of health for the foot and 100 is the best 
possible condition. Furthermore, the software also provides graphical images of the outcomes.

Table 1. Basic domains of foot health assessed by the Foot Health Status Questionnaire. Section 1 domains.

\begin{tabular}{|c|c|c|c|c|}
\hline Domain & Item & Theoretical Construct & $\begin{array}{l}\text { Meaning of Lowest } \\
\text { Score (0) }\end{array}$ & $\begin{array}{l}\text { Meaning of Highest Score } \\
\text { (100) }\end{array}$ \\
\hline Foot pain & 4 & $\begin{array}{l}\text { Type, severity and duration. } \\
\text { Evaluation of foot pain in terms } \\
\text { of type of pain, severity and } \\
\text { duration. }\end{array}$ & $\begin{array}{l}\text { Extreme pain in the feet } \\
\text { and significant if acute } \\
\text { in nature. }\end{array}$ & Free from pain, no discomfort \\
\hline Foot function & 4 & $\begin{array}{l}\text { Evaluation of the feet in terms of } \\
\text { impact on physical functions. }\end{array}$ & $\begin{array}{l}\text { Severely limited for the } \\
\text { performance } \\
\text { numerous physical } \\
\text { activities due to their } \\
\text { feet, such as walking, } \\
\text { working and moving } \\
\text { about. }\end{array}$ & $\begin{array}{l}\text { Patients are able to carry out all } \\
\text { physical activities desired, such } \\
\text { as walking, working and } \\
\text { climbing stairs. }\end{array}$ \\
\hline $\begin{array}{l}\text { General foot } \\
\text { health }\end{array}$ & 2 & $\begin{array}{l}\text { Self-perception of the feet } \\
\text { (assessment of body image with } \\
\text { respect to feet). }\end{array}$ & $\begin{array}{l}\text { Perception of poor } \\
\text { condition and status of } \\
\text { the feet. }\end{array}$ & $\begin{array}{l}\text { Perception of excellent } \\
\text { condition and status of the feet. }\end{array}$ \\
\hline Footwear & 3 & $\begin{array}{l}\text { Lifestyle relating to footwear and } \\
\text { feet. }\end{array}$ & $\begin{array}{l}\text { Great limitations to find } \\
\text { suitable footwear. }\end{array}$ & $\begin{array}{l}\text { No problem obtaining suitable } \\
\text { footwear. No limitations with } \\
\text { respect to footwear. }\end{array}$ \\
\hline
\end{tabular}

Table 2. 13 questions of the Foot Health Status Questionnaire that assess 4 health domains of the feet: pain, function, general health and footwear.

1. What level of foot pain have you had during the past week?

2. How often have you had foot pain?

3. How often did your feet ache?

4. How often did you get sharp pains in your feet?

5. Have your feet caused you to have difficulties in your work or activities?

6. Were you limited in the kind of work you could do because of your feet?

7. How much does your foot health limit you walking?

8. How much does your foot health limit you climbing stairs?

9. How would you rate your overall foot health?

10. It is hard to find shoes that do not hurt my feet.

11. I have difficulty in finding shoes that fit my feet.

12. I am limited in the number of shoes I can wear.

13. In general, what condition would you say your feet are in?
Section 2 includes questions that reflect four general health-related domains (Table 3): general health, physical activity, social capacity, and vigor. The domains and questions in this section are largely adapted from the Medical Outcomes Study 36-Item Short-Form Health Survey [39], which has been validated for use in the Australian population [40]. Specific questions of the Foot Health Status Questionnaire that assess section II domains are shown in Table 4.

Section 3 collects socioeconomic status, comorbidity, service utilization and satisfaction information and their medical record.

\section{Ethics considerations}

This research was approved by the Research and Ethics Committee of the University of A Coruña (Spain), file number CE 10/2015. All voluntary informants gave their consent in written form before their inclusion in the study. Ethical standards for research on human beings based on the Declaration of Helsinki (World Medical Association) and the Convention of the Council of Europe on human rights and biomedicine, as well as those based on the Universal Declaration of the UNESCO on the Human Genome and Human Rights and other appropriate national or institutional organisations were preserved. 
Table 3. Definitions of the Foot Health Questionnaire. Section 2 Domains.

\begin{tabular}{llll}
\hline Domain & Theoretical Construct & $\begin{array}{l}\text { Meaning of Lowest Score } \\
(\mathbf{0})\end{array}$ & Meaning of Highest Score (100) \\
\hline General health & $\begin{array}{l}\text { Evaluation of subject's self- } \\
\text { reportedhealth status. }\end{array}$ & $\begin{array}{l}\text { Poor perception of helth } \\
\text { status. }\end{array}$ & Very good general health status. \\
Physical activity & $\begin{array}{l}\text { Evaluation of ability in terms of } \\
\text { impact on physical function. }\end{array}$ & $\begin{array}{l}\text { Severely limited in } \\
\text { performing a broad raange } \\
\text { of physical activities. }\end{array}$ & $\begin{array}{l}\text { Can perform all desired physical } \\
\text { activitues with no impairment or } \\
\text { disability. }\end{array}$ \\
Social Capacity & $\begin{array}{l}\text { Self-perceptions of ability to } \\
\text { socially interact. }\end{array}$ & $\begin{array}{l}\text { Limited ability to interact } \\
\text { without problems, socially } \\
\text { isolated. }\end{array}$ & $\begin{array}{l}\text { Good ability to interact socially } \\
\text { and experience no isolation. }\end{array}$ \\
Vigor & $\begin{array}{l}\text { Lifestyle issues to perceived } \\
\text { energyand activity participation. }\end{array}$ & Lacks energy to do things. & No problems with energy levels. \\
\hline
\end{tabular}

Table 4. Questions of the Foot Health Status Questionnaire that assess section 2 domains

14. In general, how would you rate your health?

15. The following questions ask about activities you might do during a typical day. Does your health now limit you in these activities?

a. Vigorous activities, such as running, lifting heavy objects, or (if you wanted to) your ability to participate in strenuous sports.

b. Moderate activities, such as cleaning the house, lifting a chair, playing golf or swimming.

c. Lifting or carrying bags of shopping.

d. Climbing a steep hill.

e. Climbing one flight of stairs.

f. Getting up from a sitting position.

g. Walking more than a kilometer.

h. Walking one hundred meters.

i. Showering or dressing yourself.

16. To what extent has your physical health or emotional problems interfered with your normal social activities with family, friends, neighbors or social groups?

17. These questions are about how you feel during the past month. For each question, please give the one answer that comes closest. How much of the time during the past 4 weeks:

a. Did your feet get tired?

b. Did you have a lot of energy?

c. Did your feet feel worn out?

d. Did you feel full of life?

18. During the past 4 weeks, how much of the time has your emotional problems or physical health interfered with your social activities (like visiting with friends, relatives, etc.)?
19. How true or false is each of the following statements for you?

a. I seem to get sick a little easier than other people.

b. I am as healthy as anybody I know.

c. I expect my health to get worse.

d. My health is excellent

\section{Statistical analysis}

A descriptive analysis of the variables included in the study was carried out. Categorical variables appear as absolute values and percentages. Quantitative variables include mean, standard deviation (SD) and maximum and minimum values. A chi-square test was run to compare categorical variables, whereas ANOVA and pairwise comparisons with a Bonferroni adjustment were used to examine differences between groups. Finally, a stepwise multiple linear regression was then performed to determine whether the presence of HV was independently associated with FHSQ scores for specific foot domains, namely Foot pain, Foot function, General Foot Health, Footwear and for four domains of general wellbeing as Overall Health, Physical Function, Social Capacity and Vigour.

Sample size was based on a priori power calculations. Using standard deviations obtained from preliminary data analysis [41], we determined that at least 13 subjects in each group would provide a statistical power of $80 \%$ and an alpha risk of $5 \%$, to detect a difference of $12.5 \mathrm{~mm}$ between groups on the $100 \mathrm{~mm}$ pain VAS [41].

The IBM SPSS Statistics 19 package was used for the analysis of the data. The Foot Health Status Questionnaire Version 1.03 was used to obtain quality of life scores related to foot health. 
Table 5. Socio-demographic and clinical characteristics of the sample population.

\begin{tabular}{|c|c|c|c|c|}
\hline & $\begin{array}{l}\text { Total Group } \\
\text { Mean } \pm \text { SD } \\
\text { Range } \\
\mathrm{N}=115\end{array}$ & $\begin{array}{l}\text { Male } \\
\text { Mean } \pm \text { SD } \\
\text { Range } \\
\mathrm{N}=43\end{array}$ & $\begin{array}{l}\text { Female } \\
\text { Mean } \pm \text { SD } \\
\text { Range } \\
\mathrm{N}=72\end{array}$ & $\begin{array}{l}\text { P Value } \\
\text { Male vs } \\
\text { Female }\end{array}$ \\
\hline Age, years & $\begin{array}{l}76.70 \pm 9.1 \\
(65-96)\end{array}$ & $\begin{array}{l}75.58 \pm 9.18 \\
(65-96)\end{array}$ & $\begin{array}{l}77.38 \pm 9.02 \\
(65-94)\end{array}$ & 0.308 \\
\hline Weight (kg) & $\begin{array}{l}71.38 \pm 12.1 \\
(48-105)\end{array}$ & $\begin{array}{l}77.35 \pm 10.17 \\
(53-104)\end{array}$ & $\begin{array}{l}67.82 \pm 11.81 \\
(48-105)\end{array}$ & 0.000 \\
\hline Height $(\mathrm{cm})$ & $\begin{array}{l}163.96 \pm 7.24 \\
(150-183)\end{array}$ & $\begin{array}{l}169.16 \pm 5.2 \\
(156-183)\end{array}$ & $\begin{array}{l}160.86 \pm 6.48 \\
(150-177)\end{array}$ & 0.001 \\
\hline BMI $\left(\mathrm{kg} / \mathrm{m}^{2}\right)$ & $\begin{array}{l}26.96 \pm 6.62 \\
(17.93-82)\end{array}$ & $\begin{array}{l}28.18 \pm 9.01 \\
(18.78-82)\end{array}$ & $\begin{array}{l}26.93 \pm 4.56 \\
(17.93-38.57)\end{array}$ & 0.220 \\
\hline Level of education & $\begin{array}{l}0.80 \pm 0.82 \\
(0-3)\end{array}$ & $\begin{array}{l}0.95 \pm 0.9 \\
(0-3)\end{array}$ & $\begin{array}{l}0.71 \pm 0.76 \\
(0-3)\end{array}$ & 0.001 \\
\hline
\end{tabular}

Abbreviations: BMI, body mass index; SD, standard deviation. In all the analyses, $\mathrm{P}<.05$ was considered statistically significant; 0 , no education; 1 , High school education; 2 , baccalaureate; 3 , College

\section{RESULTS}

A total of 115 people of more than 65 years of age completed the research course. The sample analysed includes $72(62.6 \%)$ women and $43(37.4 \%)$ men between 65 and 96 years of age. Table 5 shows the clinical and sociodemographic characteristics of the informants. As can be seen, most informants are overweight (BMI = $26.96 \mathrm{~kg} / \mathrm{m}^{2}$ ).

The results of a comparison between FHSQ scores of the four groups' degree of HV deformity are shown in Table 6. Section One of the FHSQ evaluates four specific foot domains, namely pain, function, health and footwear. Mean scores \pm SD were significantly high in the assessment of pain, function and foot health, and lower in footwear for all groups. Section Two gives an assessment of four domains of general wellbeing: overall health, physical function, social capacity and vigour. In this case mean scores \pm SD were significantly lower in the vigour domain when compared to those for other domains physical activity, social capacity and general health for all four groups: HV 1, HV 2, HV 3 and HV 4.

The differences between the four groups were statistically significant $(p<0.001)$ for those dimensions in the questionnaire which assessed pain, footwear, general foot health, foot function, general health and social capacity

\section{DISCUSSION}

The main purpose of this study was to describe and compare the impact of quality of life related to foot health in a sample of older adults with varying degrees of $\mathrm{HV}$ of the scores obtained with regard foot health and health in general. Maintaining proper foot health is essential to older people, as close to $75 \%$ of older adults complain of foot pain that is associated with a significant foot problem and have evidence of arthritic changes on x-ray [42]. Further, clinical foot challenges in the elderly population has been recognised as a threat to public health based on the age-related decline in foot strength and flexibility, and emerging evidence that foot problems increase the risk of falls $[43,44]$. However, based on the results of the few studies carried out on this matter. Sao et al, who declared surgery of $\mathrm{HV}$ produces a significant improvement in the quality of life [29], while Gilheany et al, reports differences in foot health status between HV and hallux rigidus in participants presenting for surgical consultation, that appear to have a negative impact on health status, hallux rigidus has a more significant impact [30].

Due to the lack of firm epidemiological data relating to $\mathrm{HV}$, it is difficult to estimate the influence that this condition has on the population [3] and the impact of the quality of life related to foot health in older people with varying degrees of $\mathrm{HV}$ is not as obvious as it appears to be. The results of the present study confirm that older people present lower scores on the dimensions related to footwear and vigour with regard foot health and health in general. Abhishek and colleagues showed that concurrent $\mathrm{HV}$ and big toe pain, but not isolated HV, associates with impaired overall health satisfaction and a low score on the physical, psychological and social domains of the World Health Organization Quality of Life-BREF[18]. 
Table 6. Comparisons of FHSQ scores with varying degrees of HV.

\begin{tabular}{|c|c|c|c|c|c|}
\hline & $\begin{array}{l}\text { HV 1 } \\
\text { Mean (SD) } \\
\text { Range N = 13 }\end{array}$ & $\begin{array}{l}\text { HV } 2 \\
\text { Mean (SD) } \\
\text { Range N = 44 }\end{array}$ & $\begin{array}{l}\text { HV } 3 \\
\text { Mean (SD) } \\
\text { Range N = 32 }\end{array}$ & $\begin{array}{l}\text { HV } 4 \\
\text { Mean (SD) } \\
\text { Range N = 26 }\end{array}$ & P Value \\
\hline Foot Pain & $\begin{array}{l}87.76 \pm 6.1 \\
(75-94)\end{array}$ & $\begin{array}{l}71.28 \pm 23.3 \\
(13-100)\end{array}$ & $\begin{array}{l}52.59 \pm 30.0 \\
(0-100)\end{array}$ & $\begin{array}{l}44.65 \pm 24.5 \\
(6-94)\end{array}$ & 0.001 \\
\hline Foot Function & $\begin{array}{l}85.31 \pm 13.4 \\
(50-100)\end{array}$ & $\begin{array}{l}78.09 \pm 20.7 \\
(19-100)\end{array}$ & $\begin{array}{l}58.69 \pm 28.5 \\
(6-100)\end{array}$ & $\begin{array}{l}53.04 \pm 27.2 \\
(13-100)\end{array}$ & 0.005 \\
\hline Footwear & $\begin{array}{l}57.54 \pm 22.2 \\
(17-83)\end{array}$ & $\begin{array}{l}36.34 \pm 25.9 \\
(0-83)\end{array}$ & $\begin{array}{l}31.22 \pm 28.9 \\
(17-83)\end{array}$ & $\begin{array}{l}11.23 \pm 15.6 \\
(0-67)\end{array}$ & 0.001 \\
\hline General Foot Health & $\begin{array}{l}84.69 \pm 13.8 \\
(60-100)\end{array}$ & $\begin{array}{l}60.34 \pm 29.3 \\
(0-100)\end{array}$ & $\begin{array}{l}45.59 \pm 29.2 \\
(0-100)\end{array}$ & $\begin{array}{l}27.62 \pm 19.1 \\
(0-60)\end{array}$ & 0.001 \\
\hline General Health & $\begin{array}{l}65.38 \pm 15.1 \\
(50-100)\end{array}$ & $\begin{array}{l}55.45 \pm 24.1 \\
(10-90)\end{array}$ & $\begin{array}{l}57.19 \pm 22.6 \\
(0-100)\end{array}$ & $\begin{array}{l}41.15 \pm 25.5 \\
(10-90)\end{array}$ & 0.038 \\
\hline Physical Activity & $\begin{array}{l}75.23 \pm 17.9 \\
(50-100)\end{array}$ & $\begin{array}{l}66.21 \pm 21.3 \\
(17-100)\end{array}$ & $\begin{array}{l}67.47 \pm 22.5 \\
(20-90)\end{array}$ & $\begin{array}{l}62.81 \pm 24.6 \\
(6-100)\end{array}$ & 0.953 \\
\hline Social Capacity & $\begin{array}{l}73.38 \pm 12.4 \\
(50-100)\end{array}$ & $\begin{array}{l}68.66 \pm 28.3 \\
(0-100)\end{array}$ & $\begin{array}{l}55.72 \pm 30.6 \\
(0-100)\end{array}$ & $\begin{array}{l}44.46 \pm 28.1 \\
(0-100)\end{array}$ & 0.003 \\
\hline Vigor & $\begin{array}{l}55.38 \pm 12.1 \\
(50-100)\end{array}$ & $\begin{array}{l}49.91 \pm 15.4 \\
(19-88)\end{array}$ & $\begin{array}{l}46.25 \pm 15.3 \\
(13-81)\end{array}$ & $\begin{array}{l}42.19 \pm 16.8 \\
(13-88)\end{array}$ & 0.006 \\
\hline
\end{tabular}

Abbreviations: FHSQ = Foot Health Status Questionnaire Surve;. SD, standard deviation. In all the analyses, $\mathrm{P}<.01$ (with a $95 \%$ confidence interval) was considered statistically significant.

In a case-controlled study between participants with and without $\mathrm{HV}$, Nix and colleagues found that $\mathrm{HV}$ negatively impacts self-reported foot pain and function, and concerns about foot appearance and footwear in otherwise healthy adults. Our results support these findings and expand them further by revealing a higher negative impact correlated with degree of $\mathrm{HV}$ severity[45]. Although, Nix (2012) reported the domains of General Physical Health, Social Capacity and Vigor were not adversely affected when comparing people with and without $\mathrm{HV}$, in our study we found significant differences in these domains when comparing the grades of severity of $\mathrm{HV}$, having a negative impact with increasing the severity of the HV [45]. A recent study used the Manchester Foot Pain and Disability Index (FPDI) (29). The FPDI includes subscales for pain (score range 0 -10 ) and function (score range $0-20$ ), with higher scores indicating more pain or self-reported functional disability. We performed our study using the validated FHSQ, and the concurrent validity between these two approaches has not yet been determined [46].

Taking into account these results, it seems necessary to point out the importance of the care and control of the foot in what regards medical and podiatric care in order to prevent the appearance of illnesses and deformities of the foot, this being a key aspect that would allow to improve older people health, quality of life and autonomy.

It seems difficult to compare the impact of these results with other studies due to differences in criteria and methodological variations, as we have not been able to find any articles relating quality of life and foot health of older people with varying degrees of HV in the literature.

There are several limitations to the study that should be acknowledged. First a larger and more diverse (individuals from various countries) sample size would be beneficial to improve the strength of the study and identify more sub-categories. In addition, expanding data collection to other countries may help to identify if there is a culture where this association does not exist and identify the mechanisms involved.

This highlights the need for further continuous research on this trend in order to find out about the different therapeutic interventions used by professionals of podiatry and medicine that might improve foot health and quality of life, not only in older people but also in the general population.

\section{Conclusions}

Older people present a negative impact on the quality of life related to foot health. There is a progressive reduction 
in health in general and foot health with increasing severity of hallux valgus deformity which appears to be associated with the presence of greater degree of $\mathrm{HV}$, regardless of gender. Therefore, proper care and control of the foot are extremely important in order to prevent the appearance or development of hallux valgus deformity along the process of controlling its functionality on the feet.

\section{Acknowledgements}

We would like to thank the staff and patients of Research, Health and Podiatry Unit., Universidade da Coruña. Spain.

\section{Declaration of funding and role of funding}

None.

\section{Conflict of interest}

The authors did not receive any financial assistance from or have any personal relationships with other people or organisations that could inappropriately influence (bias) their work.

\section{References}

[1] Menz HB (2008). Epidemiology of foot problems in older people. In: Hylton B, Menz HB, editors. Foot problems in older people: Assessment and management. London: Churchill Livingstone, 1-11.

[2] Menz HB, Lord SR (2001). Foot pain impairs balance and functional ability in community-dwelling older people. $\mathrm{J}$ Am Podiatr Med Assoc, 91: 222-232.

[3] Nix S, Smith M, Vicenzino B (2010). Prevalence of hallux valgus in the general population: a systematic review and meta-analysis. J Foot Ankle Res, 3:21.

[4] Dufour AB, Casey VA, Golightly YM, Hannan MT (2014). Characteristics Associated With Hallux Valgus in a Population-Based Foot Study of Older Adults. Arthritis Care Res, 66:1880-86.

[5] Golightly YM, Hannan MT, Dufour AB, et al. (2015). Factors associated with hallux valgus in a communitybased cross-sectional study of adults with and without osteoarthritis. Arthritis Care Res (Hoboken), 67: 791798.

[6] Aiyer A, Stewart S, Rome K (2015). The effect of age on muscle characteristics of the abductor hallucis in people with hallux valgus: a cross-sectional observational study. J Foot Ankle Res, 30 May. [Epub ahead of print].

[7] Nguyen US, Hillstrom HJ, Li W, et al. (2010). Factors associated with hallux valgus in a population-based study of older women and men: the MOBILIZE Boston Study. Osteoarthritis Cartilage, 18 (1): 41- 46.

[8] Cho NH, Kim S, Kwon DJ, Kim HA (2009). The prevalence of hallux valgus and its association with foot pain and function in a rural Korean community. J Bone Joint Surg Br, 91: 494-498.

[9] Roddy E, Zhang W, Doherty M (2008). Prevalence and associations of hallux valgus in a primary care population. Arthritis Rheum, 59:857-862.

[10] Menz H, Morris M (2005). Footwear characteristics and foot problems in older people. Gerontology, 51: 346-351.

[11] Thomas S, Barrington R (2003). Hallux Valgus. Current Orthopaedics, 17:299-307.

[12] Munuera Martínez PV, editor. El primer radio. Biomecánica y ortopodología. Santander: Exa Editores; 2012.

[13] Gilheany MF, Landorf KB, Robinson P (2008). Hallux valgus and Hallux rigidus: a comparion of impact on health related quality of life in patients presenting to foot surgeons in Australia. J Foot Ankle Res, 1:14-20.

[14] Sánchez Gómez R, Losa Iglesias ME, Becerro de Bengoa Vallejo R, editors. Estudio mediante campos electromagnéticos en la etiología del hallux abductus valgus Madrid: CERSA; 2015.

[15] Hecht PJ, Lin TJ (2014). Hallux valgus. Med Clin North Am, 98:227-232.

[16] Martínez-Nova A, Sánchez-Rodríguez R, Pérez-Soriano P, Llana-Belloch S, Leal-Muro A, Pedrera-Zamorano JD (2010). Plantar pressures determinants in mild Hallux Valgus. Gait Posture, 32:425-427.

[17] Bascarević ZLJ, Vukasinović, ZS, Bascarević VD, et al. (2011). Hallux valgus. Acta Chir Iugosl, 58:107-111.

[18] Abhishek A, Roddy E, Zhang W, Doherty M. (2010). Are hallux valgus and big toe pain associated with impaired quality of life? A crosssectional study. Osteoarthritis Cartilage, 18:923-926.

[19] Saro C, Jensen I, Lindgren U, Felländer-Tsai L (2007). Quality-of-life outcome after hallux valgus surgery. Qual Life Res, 16:731-738.

[20] O'Leary CB, Cahill CR, Robinson AW, Barnes MJ, Hong J (2013). A systematic review: the effects of podiatrical deviations on nonspecific chronic low back pain. J Back Musculoskelet Rehabil, 26:117-123.

[21] Castro-Méndez A, Munuera PV, Albornoz-Cabello M (2013). The short-term effect of custom-made foot orthoses in subjects with excessive foot pronation and lower back pain: a randomized, double-blinded, clinical trial. Prosthet Orthot Int, 37:384-390.

[22] Steinberg N, Finestone A, Noff M, Zeev A, Dar G (2013). Relationship between lower extremity alignment and hallux valgus in women. Foot Ankle Int. 34:824-831.

[23] Lafuente G, Munuera PV, Dominguez G, Reina M, Lafuente B (2011). Hallux limitus and its relationship with the internal rotational pattern of the lower limb. J Am Podiatr Med Assoc, 101:467-474.

[24] Cho N H, Kim S, Kwon DJ, Kim HA (2009). The prevalence of hallux valgus and its association with foot pain and function in a rural Korean community. $J$ Bone Joint Surg Br, 91:494-498.

[25] Shih KS, Chien HL, Lu TW, Chang CF, Kuo CC (2014). Gait changes in individuals with bilateral hallux valgus reduce first metatarsophalangeal loading but increase knee abductor moments. Gait Posture, 40:38-42. 
[26] Menz HB. Lord SR (2005). Gait instability in older people with hallux valgus. Foot Ankle Int, 26:483-489.

[27] Menz HB, Morris ME, Lord SR. (2006). Foot and ankle risk factors for falls in older people: a prospective study. J Gerontol A Biol Sci Med Sci, 61:866 -870.

[28] Mickle KJ, Munro BJ, Lord SR, Menz HB, Steele JR. (2009). ISB Clinical Biomechanics Award 2009: toe weakness and deformity increase the risk of falls in older people. Clin Biomech (Bristol, Avon), 24:787-791.

[29] Saro C, Jensen I, Lindgren U, Fellander-Tsai L (2007). Quality-of-life outcome after hallux valgus surgery. Qual Life Res, 16:731-738.

[30] Gilheany MF, Landorf KB, Robinson P (2008). Hallux valgus and hallux rigidus: a comparison of impact on a health related quality of life in patients presenting to foot surgeons in Australia. J Foot Ankle Res, 1:1-14.

[31] Borman P, Ayhan F, Tuncay F, Sahin M (2012). Foot problems in a group of patients with rheumatoid arthritis: an unmet need for foot care. Open Rheumatol J, 6:290-295.

[32] Menz HB, Munteanu SE (2005). Radiographic validation of the Manchester scale for the classification of hallux valgus deformity. Rheumatology (Oxford), 44:10611066.

[33] Garrow AP, Papageorgiou A, Silman AJ, Thomas E, Jayson MI, Macfarlane GJ (2001). The grading of hallux valgus. The Manchester Scale. J Am Podiatr Med Assoc, 91:74-78.

[34] Nix S, Russell T, Vicenzino D, Smith M (2012). Measured on Digital Photographs. J Orthop Sports Phys Ther, 42:642-648.

[35] Menz HB, Tiedemann A, Kwan MMS, Latt MD, Lord SR (2003). Reliability of clinical tests of foot and ankle characteristics in older people. J Am Podiatr Med Assoc, 93: 380-387.

[36] Bennett PJ, Patterson C, Wearing S, Baglioni T (1998). Development and validation of a questionnaire designed to measure foot-health status. J Am Podiatr Med Assoc, 88:419-428.

[37] Bennett PJ, Patterson C, Dunne MP (2001). Healthrelated quality of life following podiatric surgery. J Am Podiatr Med Assoc 91:164-173.

[38] Landor KB, Keenan AM (2002). An evaluation of two foot-specific, health-related quality-of-life measuring instruments. Foot Ankle Int, 23:538-546.

[39] Ware JE Jr, Sherbourne CD (1992). The MOS 36-item short-form health survey (SF-36). I. Conceptual framework and item selection. Med Care, 30:473-483.

[40] Bennet PJ, Patterson C (1998). The Foot Health Status Questionnaire (FHSQ): a new instrument for measuring outcomes of footcare. Aust J Podiatr Med 32: 87-92.

[41] Landorf KB, Radford JA (2008). Minimal important difference: values for the Foot Health Status Questionnaire, Foot Function Index and Visual Analogue Scale. Foot, 18:15-19.

[42] Mitty E (2009). Nursing care of the aging foot. Geriatr Nurs, 30:350-354.

[43] Najafi B, de Bruin ED, Reeves ND, Armstrong DG, Menz HB (2013). The role of podiatry in the prevention of falls in older people: a JAPMA special issue. J Am Podiatr Med Assoc, 103:452-456.

[44] Cockayne S, Adamson J, Corbacho Martin B, Fairhurst C, Hewitt C, Hicks K, et al (2014). The REFORM study protocol: a cohort randomised controlled trial of a multifaceted podiatry intervention for the prevention of falls in older people, BMJ Open, Dec 17. [Epub ahead of print].

[45] Nix SE, Vicenzino BT, Smith MD (2012). Foot pain and functional limitation in healthy adults with hallux valgus: a cross-sectional study. BMC Musculoskelet Disord, 13:197

[46] Hurn SE, Vicenzino B, Smith MD (2015). Functional Impairments Characterizing Mild, Moderate, and Severe Hallux Valgus. Arthritis Care Res (Hoboken), 67:80-88. 